\title{
PROJECT BASED LEARNING DI PROVINSI KEPULAUAN RIAU MELALUI PROGRAM PEJUANG MUDA 2021 UNTUK MENINGKATKAN KESEJAHTERAAN SOSIAL
}

\author{
Zufri Hasrudy Siregar $^{1 *}$, Mawardi $^{2}$, Adi Widarma ${ }^{3}$, Prinsi Rigitta ${ }^{4}$ \\ ${ }^{1}$ Teknik Mesin, Fakultas Teknik, Universitas Asahan, Jalan Jend. Ahmad Yani, Kisaran Naga, Kec. \\ Kisaran Tim., Kisaran, Sumatera Utara 21216 \\ ${ }^{2,4}$ Teknik Mesin, Fakultas Teknik, Universitas Al-Azhar, Jl. Pintu Air IV No.214, Kwala Bekala, Kec. \\ Medan Johor, Kota Medan, Sumatera Utara 20143 \\ ${ }^{3}$ Teknik Informatika, Fakultas Teknik, Universitas Asahan, Jalan Jend. Ahmad Yani, Kisaran Naga, \\ Kec. Kisaran Tim., Kisaran, Sumatera Utara 21216 \\ * rudysiregar7@gmail.com
}

\begin{abstract}
ABSTRAK. Pejuang Muda adalah laboratorium sosial tempat mahasiswa dapat menerapkan ilmu dan pengetahuannya untuk membuat dampak sosial yang nyata. Dengan berfokus pada bantuan sosial, fakir miskin dan lansia, pola hidup sehat dan fasilitas umum. Program ini berlatar belakang adalah angka kemiskinan di Indonesia $10 \%$ dari jumlah penduduk sekitar 2,5 juta penduduk. Dalam pelaksanaan tersebut, Mentor berperan aktif dan mengarahkan pejuang muda dalam melakukan Project Base Learning yang bermanfaat untuk masyarakat. Dimana terdapat tujuh proposal yang di ajukan dan di implementasikan di lokasi masing masing yang pendanaannya diakomodasi oleh Kementerian dan Dinas sosial setempat. Tujuan pengabdian ini adalah memastikan dan memberikan data yang benar dan sesuai terkait data verifikasi dan validasi Pusdatin Kemensos dan mewujudkan solusi konkret di masyarakat guna meningkatkan kesejahteraan dan kesehatan masyarakat dan lingkungan.
\end{abstract}

Kata kunci: Pejuang Muda, Kepri, Project Based Learning, Kemensos

ABSTRACT. Pejuang Muda is a social laboratory where students can apply their knowledge and knowledge to make a real social impact. By focusing on social assistance, the poor and the elderly, healthy lifestyles, and public facilities. The background of this program is that the poverty rate in Indonesia is $10 \%$ of the total population of around 2.5 million people. In this implementation, Mentors play an active role and direct young fighters in carrying out Project Base Learning that is beneficial to the community. There are seven proposals submitted and implemented in their respective locations whose funding is accommodated by the Ministry and the local Social Service. The purpose of this service is to ensure and provide correct and appropriate data related to the verification and validation data of the Ministry of Social Affairs Center and to realize concrete solutions in the community to improve the welfare and health of the community and the environment.

Keywords: Young Fighters, Riau Islands, Project Based Learning, Ministry of Social Affairs

Terima 29 Desember 2021 Terima dan di revisi 5 Januari 2022 Disetujui 6 Januari 2022

\section{PENDAHULUAN}

Pejuang Muda merupakan bagian dari kebijakan Mensos dalam Program Merdeka Belajar-Kampus Merdeka Kemendikbudristek (Fahlevi, 2021). Pejuang Muda adalah laboratorium sosial tempat mahasiswa dapat menerapkan ilmu dan pengetahuannya untuk membuat dampak sosial yang nyata. Dalam program 20 SKS ini, mahasiswa didorong untuk belajar dari warga, bekerja sama dengan pemerintah daerah, tokoh masyarakat, tokoh agama setempat, dan seluruh pemangku kepentingan yang terlibat dalam mobilisasi masyarakat (Kemensos, 2021b) Kategori program berfokus pada beberapa kategori yaitu

1. Pengembangan Program Bantuan Sosial Pengembangan bantuan sosial yang berkelanjutan. Plus, kegiatan memverifikasi dan validasi (quality 
assurance) penerima bantuan sosial dan sembako.

2. Pemberdayaan miskin dan Lansia Inovasi program sosial untuk membantu fakir miskin dan atau lansia.

3. Pola hidup sehat dan kesehatan lingkungan Pengembangan program kesehatan lingkungan bagi masyarakat kurang mampu serta memperkuat gaya hidup sehat di seluruh level masyarakat.

4. Fasilitas untuk kepentingan umum

Pembangunan fasilitas untuk kepentingan umum di wilayah pasca bencana (Nusa Tenggara Timur) seperti micro-hydro, rutilahu dan community center

Program ini mendorong mahasiswa menguasai berbagai keilmuan dan keterampilan untuk ruang belajar dan ekspresi dalam membuat perubahan sosial.

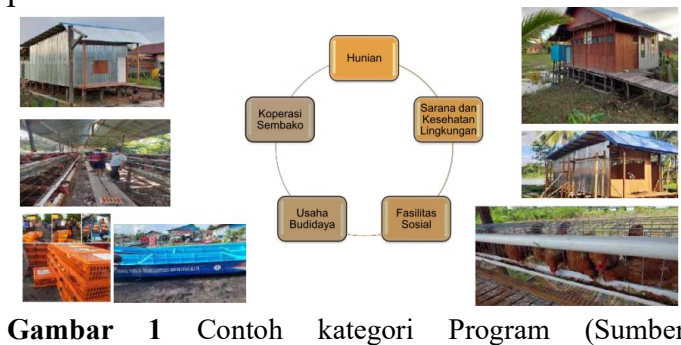

(Kemensos, 2021a)

Konsep dan tujuan dari program tersebut sangat jelas merupakan program yang menyentuh langsung pada masyarakat ekonomi menegah ke bawah di mana berdasarkan data pada 15 Juli 2021, BPS merilis laporan yang melaporkan bahwa 27,54 juta penduduk Indonesia miskin, $10,14 \%$ pada Maret 2021. Angka kemiskinan pada Maret 2021 sedikit lebih rendah dibandingkan September 2020, namun masih lebih tinggi dibandingkan sebelum pandemi September 2019.(Statistik, 2021)

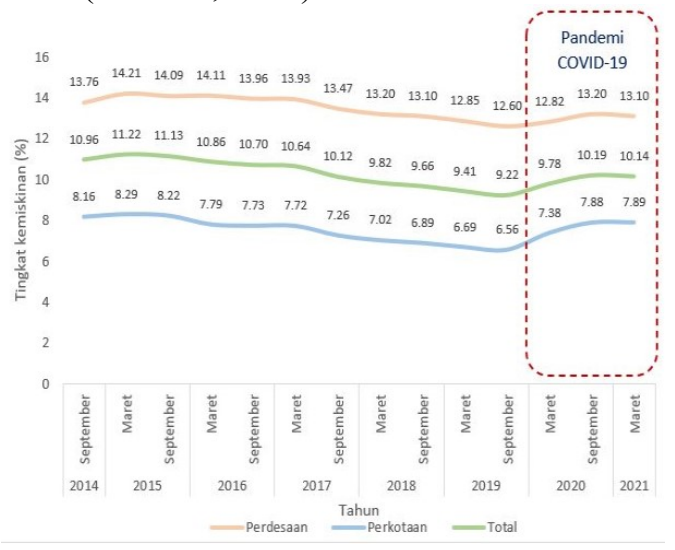

Gambar 2 Tingkat kemiskinan Nasional 2014-2021 (Sumber:(Statistik, 2021))

Sementara itu, Pejuang Muda yang dilaksanakan di Kepulauan Riau terdapat tujuh kabupaten kota yaitu :

1. Kota Batam

2. Kota Tanjungpinang

3. Kabupaten Bintan

4. Kabupaten Karimun

5. Kabupaten Kepulauan Anambas

6. Kabupaten Lingga

7. Kabupaten Natuna

Di mana pelaksanaannya berdasarkan data Badan Pusat Statistik (BPS) mencatat, jumlah penduduk miskin pada Provinsi Kepulauan Riau (Kepri) dalam September 2021 mencapai 137,75 ribu orang. Jumlah itu berkurang sebesar 6.071 orang ketimbang dalam Maret 2021, sebanyak 144,46 ribu orang. Adapun persentase penduduk miskin pada wilayah perkotaan dalam Maret 2021 sebanyak 5,72\%, turun sebagai 5,37\% dalam September 2021. Sedangkan persentase penduduk miskin pada wilayah perdesaan dalam Maret 2021 sebanyak $11,10 \%$, pula turun sebagai $10,45 \%$ dalam September 2021.(Medcom, 2022).

Sebagai Mentor Pejuang Muda, ada beberapa hal yang penting diperhatikan yaitu mendampingi Mahasiswa yang lolos pada program dapat merealisasikan empat pilar Pejuang Muda dan mewujudkan base project yang dikompetisikan secara Nasional serta didanai oleh Kemensos, Kemendikbudristek dan Kemenag serta bagai yang tidak lolos pendanaan akan dilakukan pendanaan kemitraan seperti kamubisa.com

Kepulauan Riau merupakan rumah bagi beragam suku dan budaya. tersebar di daerah tersebut. Suku-suku di Kepulauan Riau yaitu Akit, Bonai, Talang Mamak, Sakai, Suku Laut dan Hutan, Suku Melayu. Juga suku-suku pendatang seperti suku Jawa, Minang dan Batak. Beberapa suku ini masih menganut kerajinan tradisional. dan budaya.

\section{METODE}

Dalam pengabdian tersebut, digunakan metode Project Base Learning yang berbasis online dan offline. Project Base Learning (PBL) adalah Implementasi dari kegiatan Pembelajaran aktif dimana proses pembelajaran menghubungkan antara teknologi dan masalah kehidupan sehari hari (Rati et al., 2017) 
1. Metode Online : Mahasiswa membuat digital campaign \& fundraising untuk mendukung kegiatannya dalam memberikan dampak sosial (Kemensos, 2021a). Pada aktivitas online tersebut, mentor juga memberikan bimbingan melalui aplikasi Zoom yang dilakukan tiap minggu selama aktivitas mentoring dilakukan serta menyeleksi

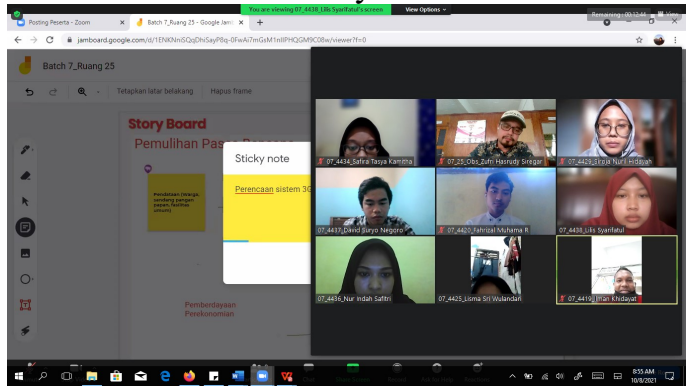

Gambar 3 aktivitas onlie seleksi pejuang muda(Sumber: data diolah, 2021)

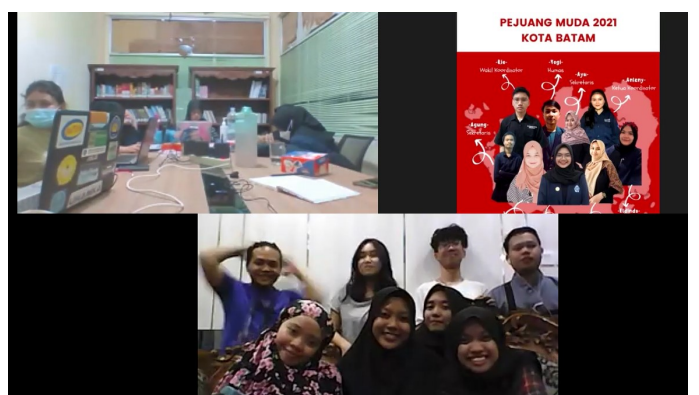

Gambar 4 aktivitas online pendampingan (Sumber: data diolah, 2021)

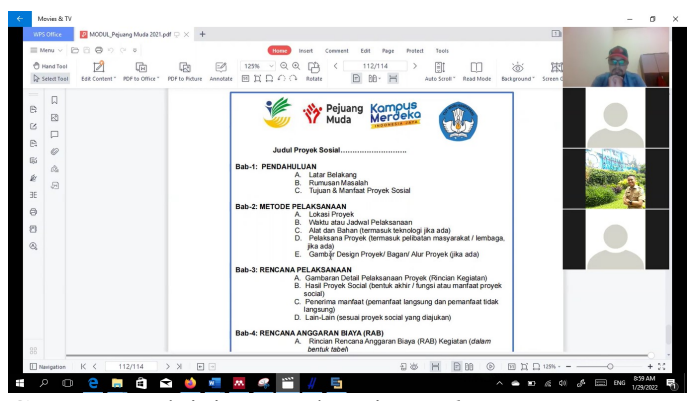

Gambar 5 aktivitas pendampingan base project secara Online (Sumber: data diolah, 2021)

Untuk mendukung kegiatan yang dilakukan secara online, Pejuang Muda di Kepri juga di berikan bekal pembelajaran secara daring menggunakan SPADAINDONESIA dengan alamat url https://adminspada.kemdikbud.go.id

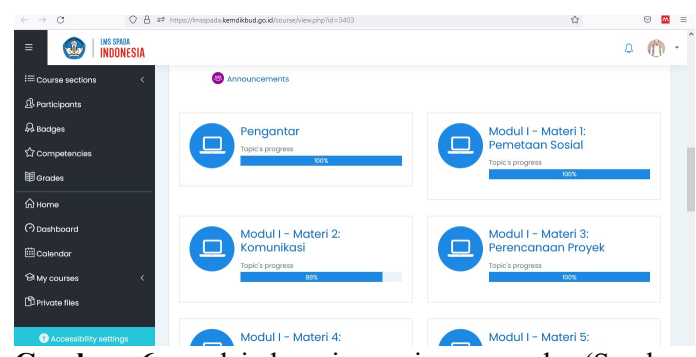

Gambar 6 spadaindonesian pejuang muda (Sumber: spadaindonesia, 2021)

Serta dilakukan penilaian pada aktivitas setiap hari kegiatan dan penilaian pada setiap modul dimana materi yang dinilai adalah komunikasi, kewirausahaan sosial, mitigasi dan pengawasan, pengembangan diri. Untuk grup task atau penugasan kelompok dinilai oleh mentor yaitu base project yang dilakukan di Kepri

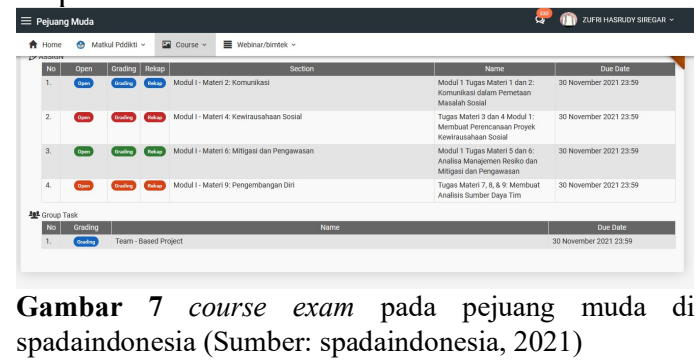

2. Metode Offline : Mahasiswa berkolaborasi/magang dengan Kementerian Sosial, balai, atau panti sosial lokal untuk mengatasi permasalahan sosial di wilayah tersebut (Kemensos, 2021a). untuk hal ini, mentor melakukan visit dan pendampingan langsung pada tujuh kabupaten kota yang berada di Kepri dengan berkolaborasi pada stakeholder di lapangan

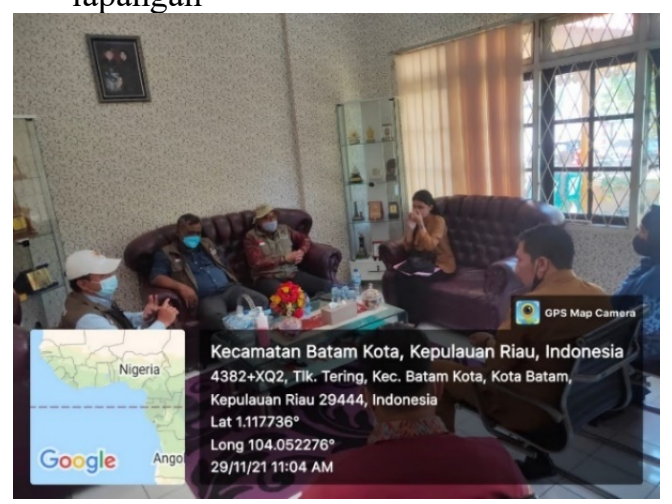

Gambar 8 Kordinasi ke Dinas Sosial Batam (Sumber: data diolah, 2021) 


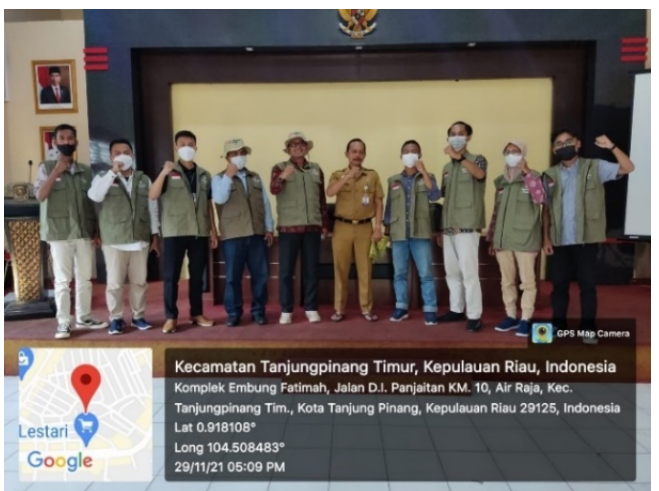

Gambar 9 Kordinasi ke Dinas Sosial Tanjung Pinang (Sumber: data diolah, 2021)

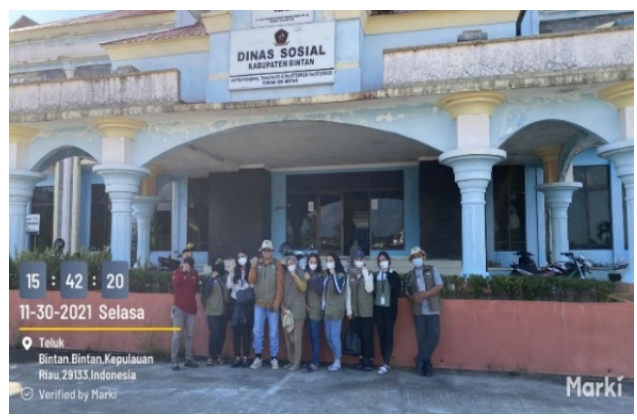

Gambar 10 Kordinasi ke Dinas Sosial Bintan (Sumber: data diolah, 2021)

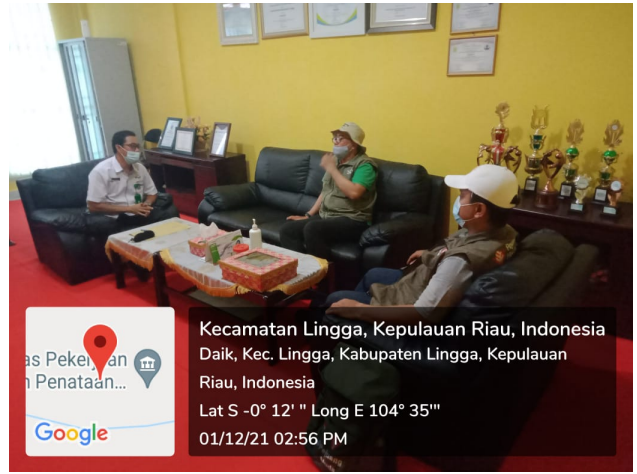

Gambar 11 Kordinasi ke Dinas Sosial Lingga (Sumber: data diolah, 2021)

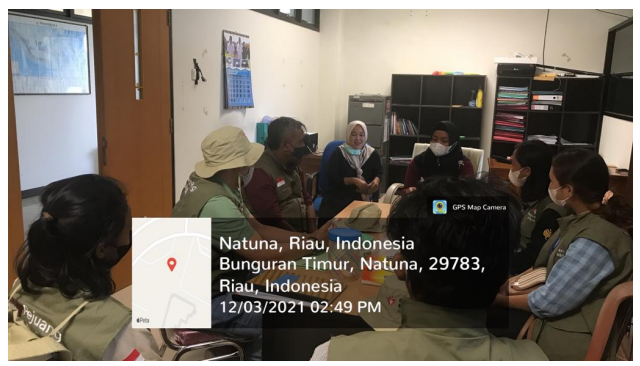

Gambar 12 Kordinasi ke Dinas Sosial Natuna (Sumber: data diolah, 2021)

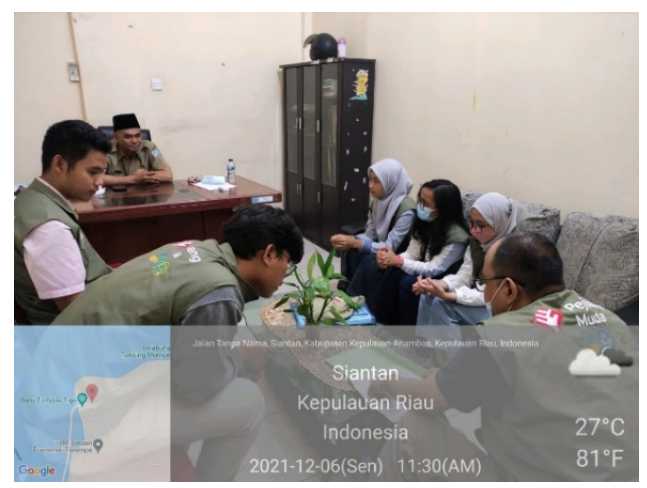

Gambar 13 Kordinasi ke Dinas Sosial Anambas (Sumber: data diolah, 2021)

\section{HASIL DAN PEMBAHASAN}

Dari kegiatan yang dilakukan semalam 3 bulan tersebut, dihasilkan solusi sosial yang dikembangkan berdasarkan sumber daya yang ada di tempat tersebut yaitu :

\section{Kota Batam}

Pejuang muda di Batam terdiri dari sembilan orang di antara nya tiga pria dan enam wanita dimana Implementasi PBL yaitu "Tembesipreneur: Pemberdayaan Pondok Tani Dalam Meningkatkan UMKM Kreatif Melalui Pengelolaan Singkong Menjadi Mocaf"

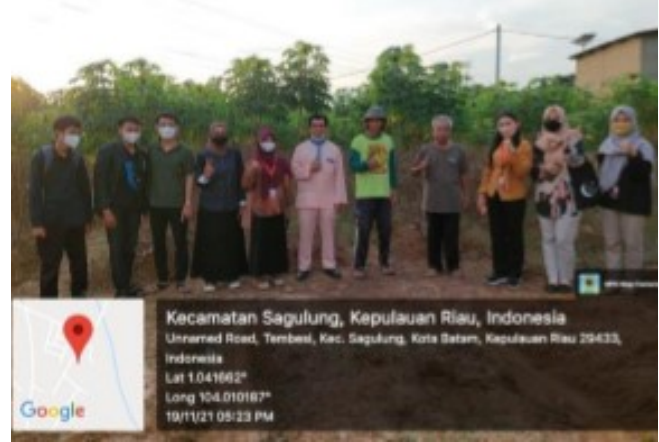

Gambar 14 Kegiatan Pengolahan Singkong menjadi Mocaf (Sumber: data diolah, 2021)

\section{Kota TanjungPinang}

Pejuang Muda Tanjung Pinang terdiri dari tujuh orang yaitu enam orang pria dan satu orang wanita. Implementasi PBL " $U M K M$ Inovasi Tanjak berbasis sosial dan budaya untuk mengentaskan kemiskinan serta menciptakan lapangan pekerjaan di Tanjungpinang" 


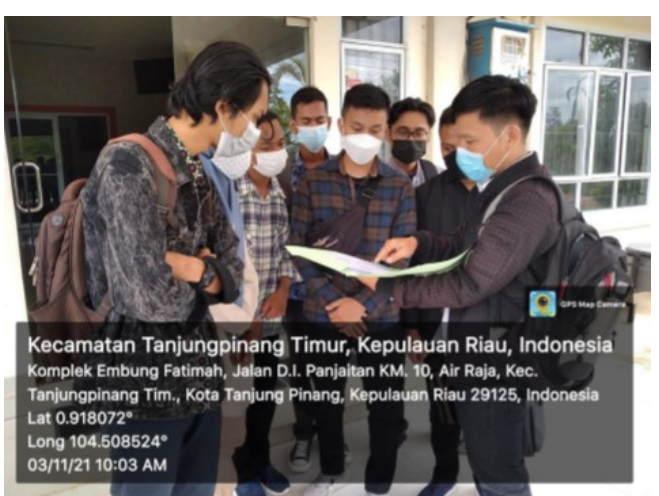

Gambar 15 Kegiatan Inovasi Tanjak kreasi (Sumber: data diolah, 2021)

\section{Kabupaten Bintan}

Pejuang Muda Bintan terdiri dari delapan orang yaitu satu pria dan tujuh wanita. Implementasi PBL yaitu "IPEKA EMPAT (Ibu-ibu Penguat Ekonomi Keluarga Pengolahan Buah Perepat)"

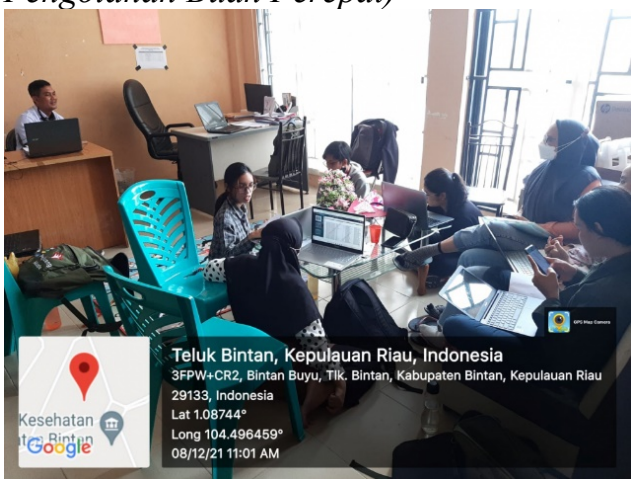

Gambar 16 Kegiatan IPEKA EMPAT (Sumber: data diolah, 2021)

\section{Kabupaten Karimun}

Pejuang Muda Karimun terdiri dari sembilan orang yaitu tiga pria dan enam wanita Implementasi PBL yaitu "Program sosial bedah Desa Pongkar"

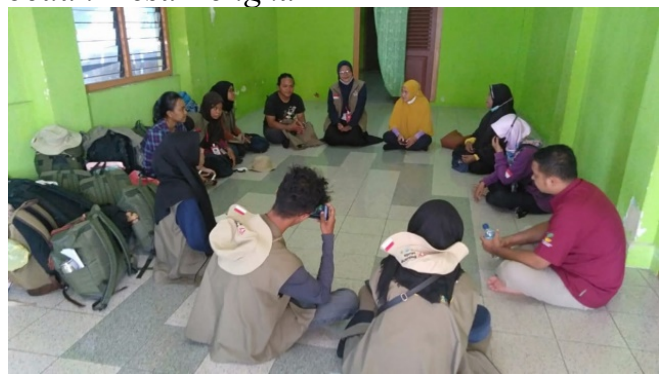

Gambar 17 Kegiatan bedah Desa (Sumber: data diolah, 2021)

\section{Kabupaten Anambas}

Pejuang Muda Anambas terdiri delapan orang yaitu lima pria dan tiga wanita, implementasi
PBL yaitu "Pengadaan rumah produksi pada desa wisata kampung cumi"

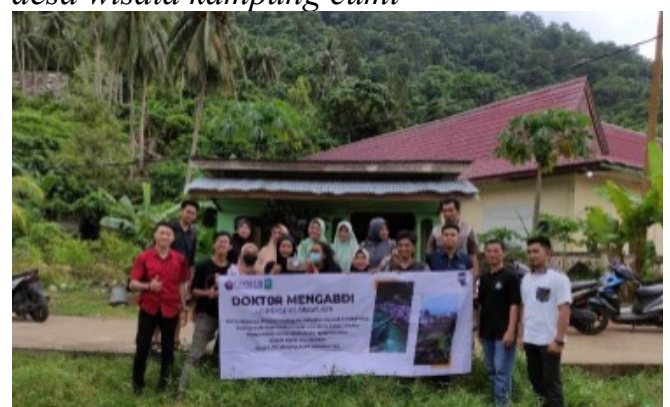

Gambar 18 Kegiatan (Sumber: data diolah, 2021)

\section{Kabupaten Lingga}

Pejuang Muda Lingga terdiri sembilan orang yaitu dua pria dan tujuh wanita implementasi PBL yaitu "Ikan ayam ayam sumber kesejahteraan masyarakat desa Batu Belubang"

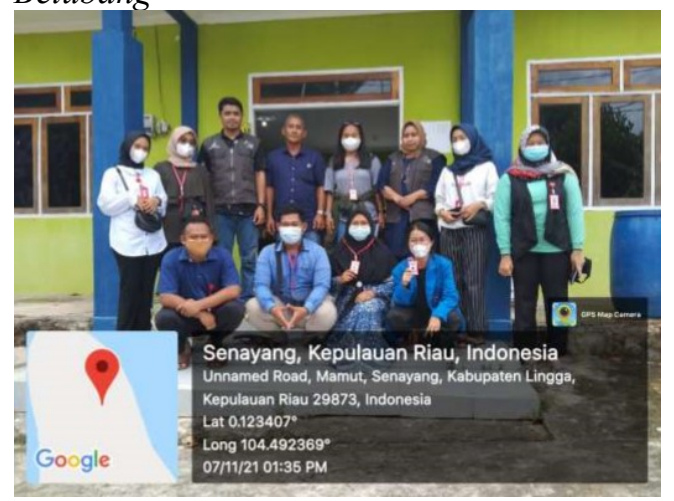

Gambar 19 Kegiatan survei (Sumber: data diolah, 2021)

\section{Kabupaten Natuna}

Pejuang Muda Lingga terdiri tujuh orang yaitu tiga pria dan empat wanita implementasi PBL yaitu "Junior Centre sebagai integratif guna meningkatkan kualitas anak remaja di Kabupaten Natuna"

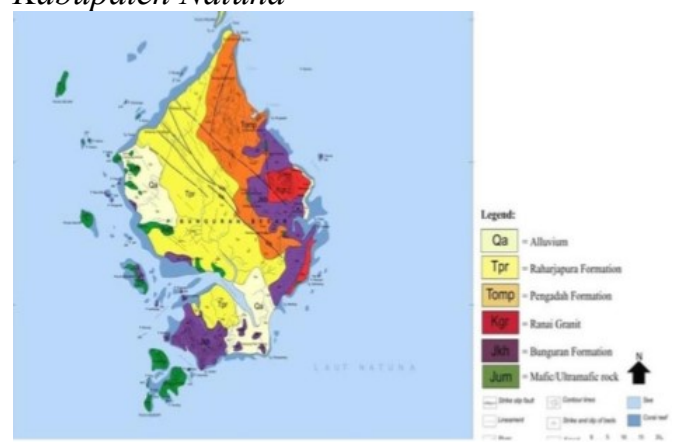

Gambar 20 Lokasi Kegiatan Natuna (Sumber: data diolah, 2021) 


\section{SIMPULAN}

Adapun kesimpulan dari kegiatan tersebut yaitu

1. Pejuang Muda Kepri telah melakukan Project Base Learning guna meningkatkan kesejahteraan sosial masyarakat

2. Verifikasi dan validasi data dilakukan berdasarkan data Pusdatin yang bertujuan untuk memberikan data baru dan penambahan data lama

3. Kegiatan yang dilakukan di Kepulauan Riau di respons baik oleh stakeholder setempat yaitu Dinas Sosial dan Masyarakat setempat dibuktikan dengan hasil PBL yang diterima di masyarakat dan didukung oleh Dinas

\section{UCAPAN TERIMAKASIH}

Dengan selesaikan pengabdian terhadap masyarakat ini di ucapkan banyak terima kasih kepada :

1. Kementerian Sosial, Kemendikbudristek Dikti, Kementerian Agama

2. Dinas Sosial Kepri, Batam, Tanjungpinang, Bintan, Karimun, Anambas, Lingga, Natuna

3. Teman teman Mentor angkatan-1 serta Mentor Internal yaitu Bapak Muji Trisilo, S.Sos, Bapak Rosendra Ikhwan, S.Sos

\section{DAFTAR PUSTAKA}

Fahlevi, F. (2021). Kemensos Gelontorkan Rp 178 Miliar untuk Program Pejuang Muda - Tribunnews.com. Tribunnews.Com.

https://www.tribunnews.com/nasional/20 21/10/13/kemensos-gelontorkan-rp-178miliar-untuk-program-pejuang-muda

Kemensos. (2021a). Pejuang Muda Ide dan pengemasan program Pejuang Muda Kemensos. moz-extension://67bbee3936de-444d-996b22f97271d09e/enhancedreader.html?openApp\&pdf=https $\% 3 \mathrm{~A} \% 2$ F\%2Fft.unud.ac.id\%2Fprotected\%2Fstor age $\% 2$ Flampiran post $\% 2 \mathrm{Fc} 711 \mathrm{bcb} 4 \mathrm{~cd} 9$ 645e1f0d1e2129b6c56c2.pdf

Kemensos. (2021b). Pejuang Muda Kemensos. Kemensos.

https://pejuangmuda.kemensos.go.id/

Medcom. (2022). Penduduk Miskin di Kepri Berkurang 6.071 Orang - Medcom.id.
Medcom.

https://www.medcom.id/nasional/daerah/ Rb1GOEYK-penduduk-miskin-di-kepriberkurang-6-071-orang

Rati, N. W., Kusmaryatni, N., \& Rediani, N. (2017). Model Pembelajaran Berbasis Proyek, Kreativitas dan Hasil Belajar Mahasiswa. JPI: Jurnal Pendidikan Indonesia, 6(1), 60-71.

Statistik, B. P. (2021). Badan Pusat Statistik. BPS.

https://www.bps.go.id/pressrelease/2021/ 07/15/1843/persentase-penduduk-miskinmaret-2021-turun-menjadi-10-14persen.html 